\title{
Functional outcome of peritrochanteric fracture fixation with modified gamma nail using tri-wire anchorage
}

\author{
Jayanta Mukherjee, Mujtaba Ahmad, Swagatam Jash*, Kartick Nasipuri, \\ Pankaj K. Kushwaha
}

Department of Orthopaedics, KPC Medical College and Hospital, Kolkata, West Bengal, India

Received: 27 November 2021

Revised: 02 January 2022

Accepted: 05 January 2022

*Correspondence:

Dr. Swagatam Jash,

E-mail: swagatamjash@gmail.com

Copyright: (C) the author(s), publisher and licensee Medip Academy. This is an open-access article distributed under the terms of the Creative Commons Attribution Non-Commercial License, which permits unrestricted non-commercial use, distribution, and reproduction in any medium, provided the original work is properly cited.

\section{ABSTRACT}

Background: Pertrochanteric fractures comprise almost $50 \%$ of all proximal femoral fractures. Being common in elderly people, the quality of life deteriorates until the fracture is stabilized, followed by early mobilization. Intramedullary devices have been proven to improve biomechanics. In our study, we adopted modified gamma nail with additional tri-wire anchorage construct, which further stabilizes the rotational torque.

Methods: A prospective study was undertaken on 39 skeletally mature patients of both sexes, with per-trochanteric fracture, from January 2019 to April 2020. The study included 23 females and 16 males. the 34 underwent CRIF while 5 underwent ORIF. One patient was lost to follow-up. Clinico-radiological evaluations of the patients were done for 12 months. Functional evaluation was based on the modified Harris hip score (mHHS). Statistical analysis was done by SPSS (version 27.0; SPSS Inc., Chicago, IL, USA) and GraphPad Prism version 5.

Results: The study showed $100 \%$ union rate. Radiologically at 3 months, the fracture united in all patients. At 6 months postoperatively all patients were ambulatory with or without walking aids. One patient had tri-wire cut through and one had tri-wire back-out. HHS was an average of 79 at 3 months representing a fair outcome. This increased to 90 at 6 months representing an excellent outcome.

Conclusions: Modified gamma nail with tri-wire anchorage has distinct advantages over other techniques. It allows for early weight-bearing and mobilization with lesser complications. The tri-wire construct further provides additional rotational stability in osteoporotic bone.

Keywords: Per-trochanteric fracture, Modified gamma nail, Tri-wire anchorage

\section{INTRODUCTION}

Pertrochanteric fractures involve those occurring in the region extending from the extracapsular basilar neck region to the region along the lesser trochanter proximal to the development of the medullary canal. Intertrochanteric and peritrochanteric are generic term for pertrochanteric fractures. ${ }^{1}$

These fractures are associated with functional disability, loss of mobility, and dependency. Operative fixation of these fractures is a must in order to reduce mortality and morbidity rates. Due to varying fracture geometry, it poses a significant challenge to the treating surgeon. ${ }^{2}$

Intramedullary devices have theoretically been proven to improve biomechanics by providing more stability, owing to a shorter lever arm, which provides more load sharing and allows less collapse. Gamma nail is a versatile implant for fixation of pertrochanteric fractures which include trochanteric fractures of different geometry. Initially, it was called Halifax nail after the place where it was developed. A group of surgeons from Strasbourg changed the name of this nail to a universal 
one i.e., Gamma nail as the shape resembled the Greek letter. ${ }^{6}$ The nail subsequently underwent various modifications.

With this modified nail design nearly $60 \%$ of fractures could be fixed with lesser degree of reaming. Decreased mediolateral nail valgus together with shortened nail length decreased stress on the anterior, medial, and lateral cortices. This led to decreased hoop stresses inside the canal leading to fewer intraoperative and postoperative complications. ${ }^{6}$

The objective of the study was to evaluate the functional outcome of pertrochanteric fracture fixation by gamma nails.

\section{METHODS}

The study was carried out with a study population of 39 patients at KPC medical college and hospital. The duration of the study was from January 2019 to April 2020. All necessary approval and clearances were taken from the ethical and scientific committee.

\section{Study design}

The study design was a prospective study.

\section{Parameters used}

Clinico-radiological evaluations of the patients were done on sequential follow-ups for a period of 12 months. On each follow-up, the functionality of the operated limb and the radiological union of the fracture along with hardware-related complications were accounted for.

\section{Study tool}

Study tools included-patient informed consent form, case sheets for relevant history and clinical examination, instruments like measuring tapes, goniometer, and a scoring system i.e., mHSS which was filled up by both the patient as well as the treating surgeon.

All the patients were operated on by the same surgeon (the first author) along with his team of assistant surgeons. All cases were treated with the modified gamma nail with additional anchorage (Tri-wire construct).

For statistical analysis data were entered into a Microsoft excel spread-sheet and then analysed by SPSS (version 27.0; SPSS Inc., Chicago, IL, USA) and GraphPad Prism version 5 .

\section{Inclusion criteria}

Patients more than 50 years of age, patients of either sex and unilateral per-trochanteric fracture were included in the study.

\section{Exclusion criteria}

Patients less than 50 years of age, concomitant fracture of the same limb with the pertrochanteric fracture and open fracture were excluded from the study.

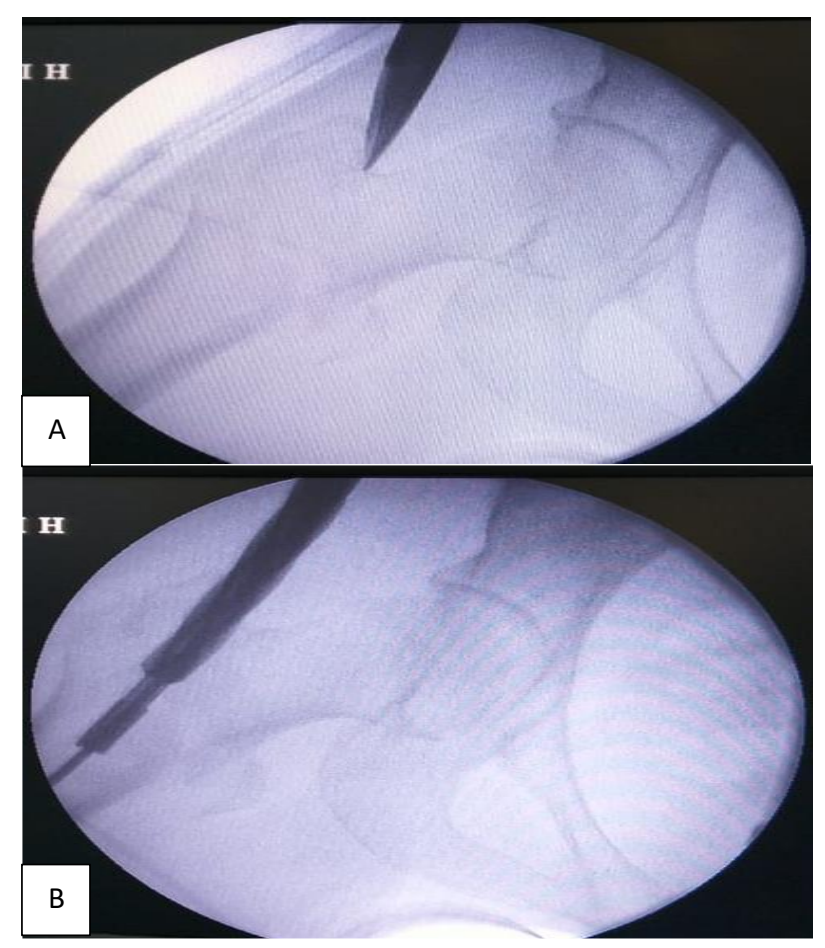

Figure 1 (A and B): Modified medial trochanteric portal; reaming of femur.

Proximal reaming over the guide pin, to a depth just below the level of the lesser trochanter is done. A balltip guide pin is placed intramedullary down the shaft of the femur to the physeal scar. Reaming of the femoral canal is done to a diameter of $1.5 \mathrm{~mm}$ larger than the diameter of the intramedullary nail. Thereafter, a proximal femoral nail of appropriate size was inserted. Nail of $10 \mathrm{~mm}$ diameter in males and $9 \mathrm{~mm}$ diameter in females were used. The nail was inserted to a depth that allowed center-center positioning in the femoral head with the lag screw. Evaluation of version of the nail on the lateral fluoroscopic view; version is considered correct when the nail, guide, and femoral neck and head are all aligned.

A small incision laterally through the skin and fascia was made and an appropriate drill sleeve was placed onto the lateral aspect of the femur. A guide pin was advanced to within $5 \mathrm{~mm}$ of the subchondral bone of the femoral head. Confirmation of appropriate center-center position in the femoral head by $\mathrm{C}$-arm was done. An appropriately sized lag screw was inserted. After releasing traction, the desired amount of compression using the compression screw was applied. Finally, the tri-wire construct was placed with the help of tri-wire introducer and pusher, under fluoroscopic guidance. Thereafter, the distal interlocking screws were placed. 


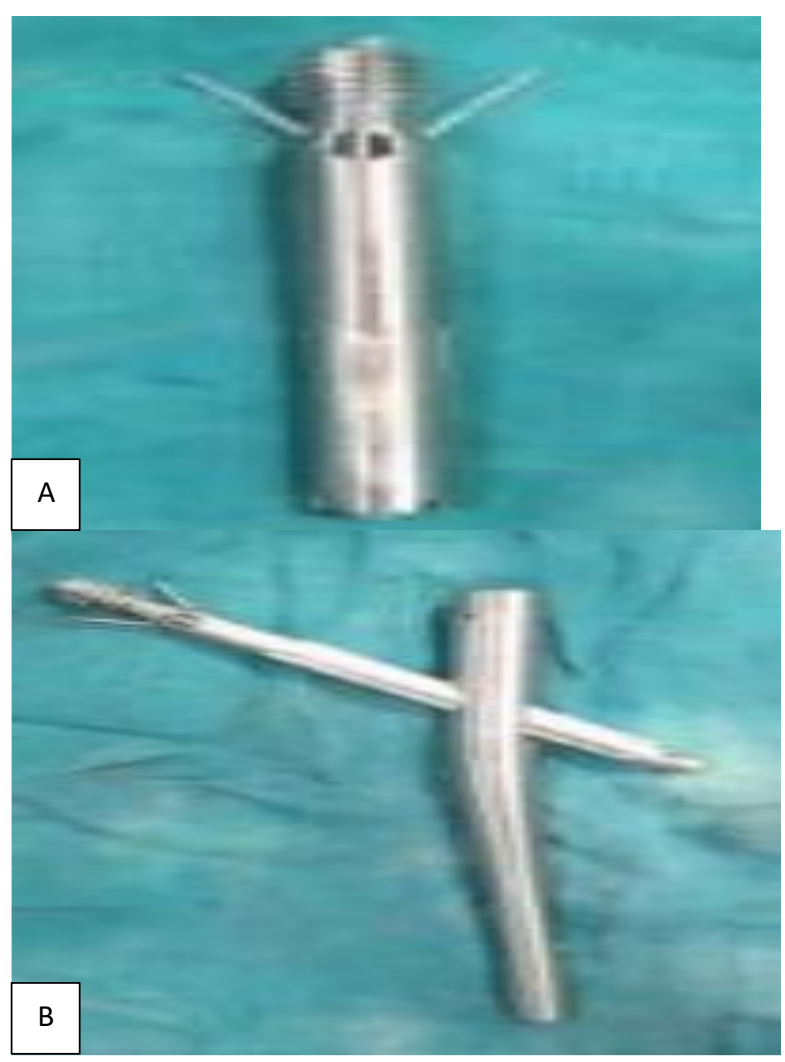

Figure 2 (A and B): Lag screw and tri-wire assembly; modified gamma nail with tri-wire construct.

The incisions were closed in layers using absorbable suture materials for the inner soft tissues and monofilament for the skin incisions. Anti-septic dressing of the incisions was done. A temporary long knee brace was applied to all patients.

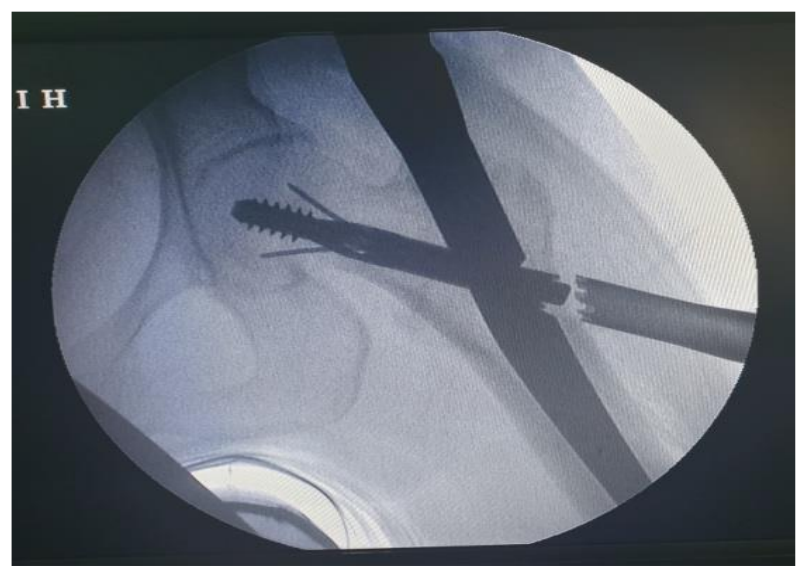

Figure 3: Intra-op image.

Postoperatively the patients were mobilized out of bed on day 1 and weight-bearing as tolerated was initiated.

Analysis was done based on the mHHS. Questioners were filled up by the patients and the treating surgeon on subsequent follow-ups.

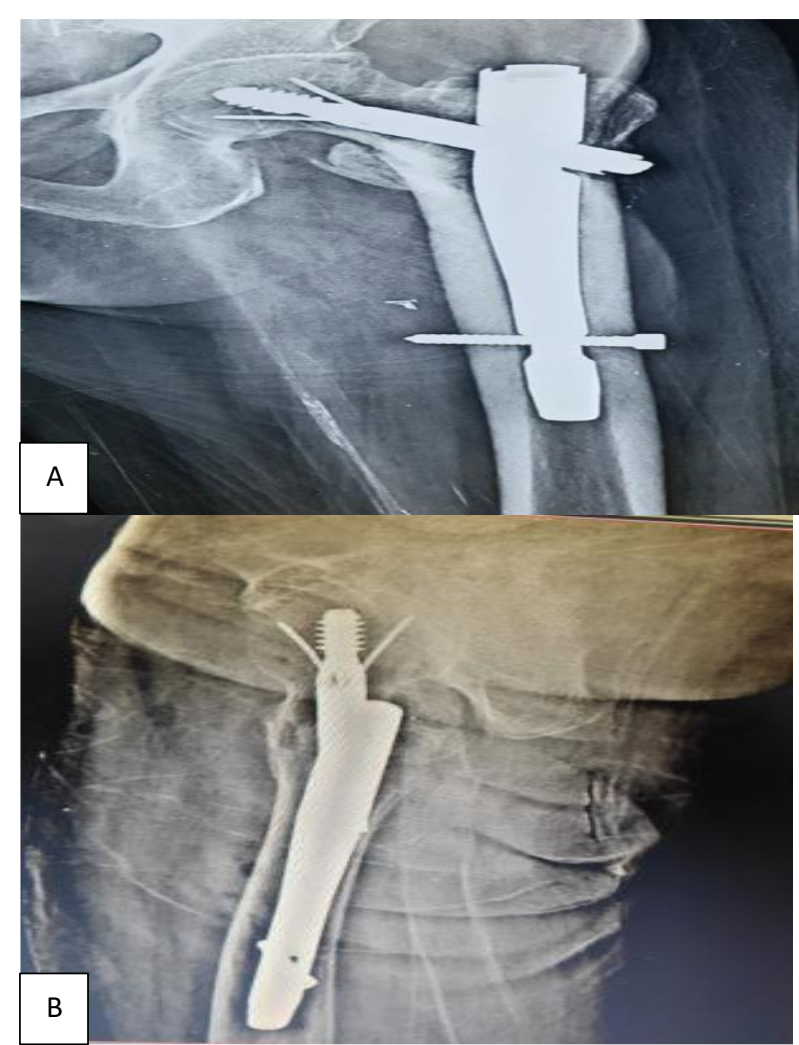

Figure 4 (A and B): Post-operative radiographs in AP and lateral views.

\section{RESULTS}

In this study, the total numbers of patients were 39 . Out of which $9(23.1 \%)$ patients were $\leq 60$ years old, 12 $(30.8 \%)$ patients were $61-70$ years old, $10(25.6 \%)$ patients were $71-80$ years old and $8(20.5 \%)$ patients were $81-90$ years old.

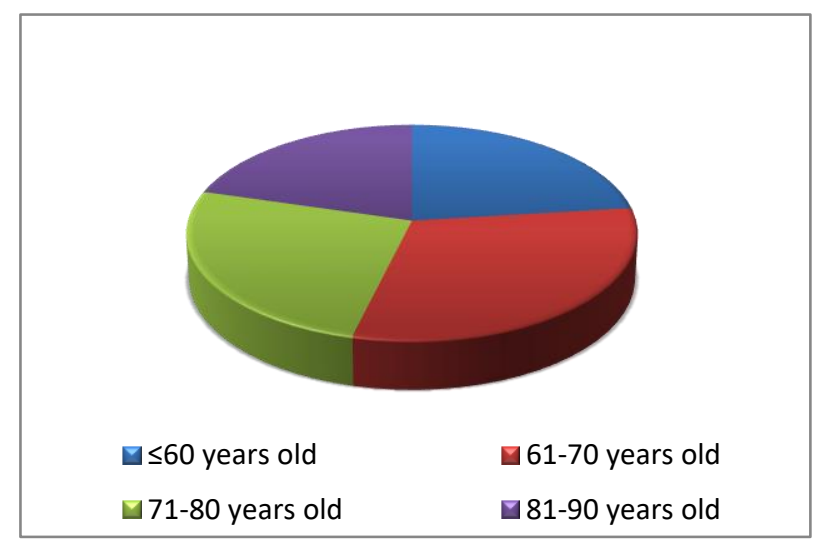

Figure 5: Age groups.

Of the 39 patients, $23(59.0 \%)$ patients were female and $16(41.0 \%)$ patient were male.

In our study, $10(26 \%)$ patients had 31A1 type, $20(51 \%)$ patients had 31A2 type, and $9(23 \%)$ patients had $31 \mathrm{~A} 3$ type fracture. 


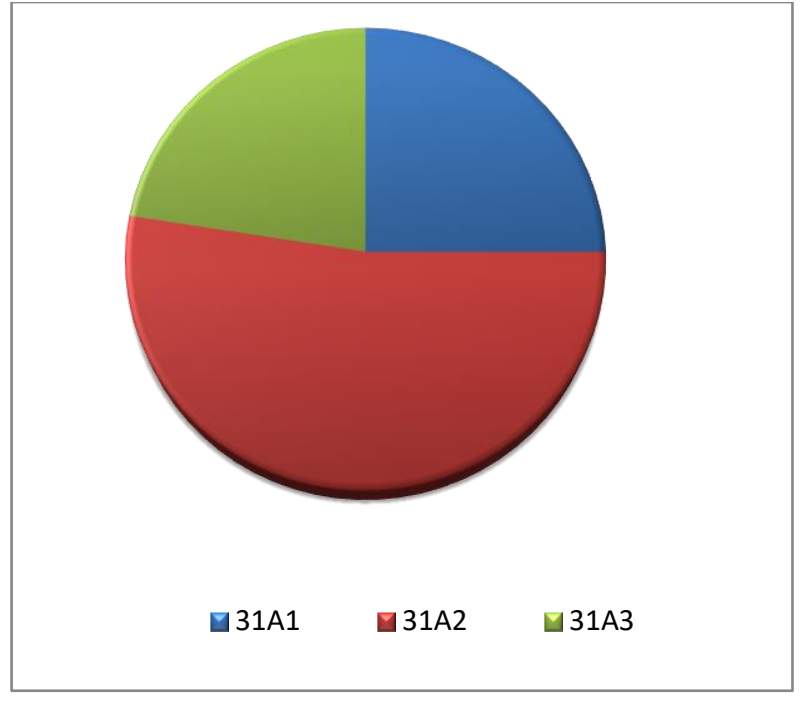

Figure 6: Fracture types.

In our study, 5 patients had given additional incision for open fracture reduction and all 39 patients have normally $2 \mathrm{~cm}$ incision for lag screw fixation and $1.5 \mathrm{~cm}$ for distal locking.

In our study $34(87 \%)$ patients undergone CRIF, average blood loss was $76 \mathrm{ml}$ while $5(13 \%)$ patients undergone ORIF and average blood loss $120 \mathrm{ml}$. And the average operating time was 48 minutes.

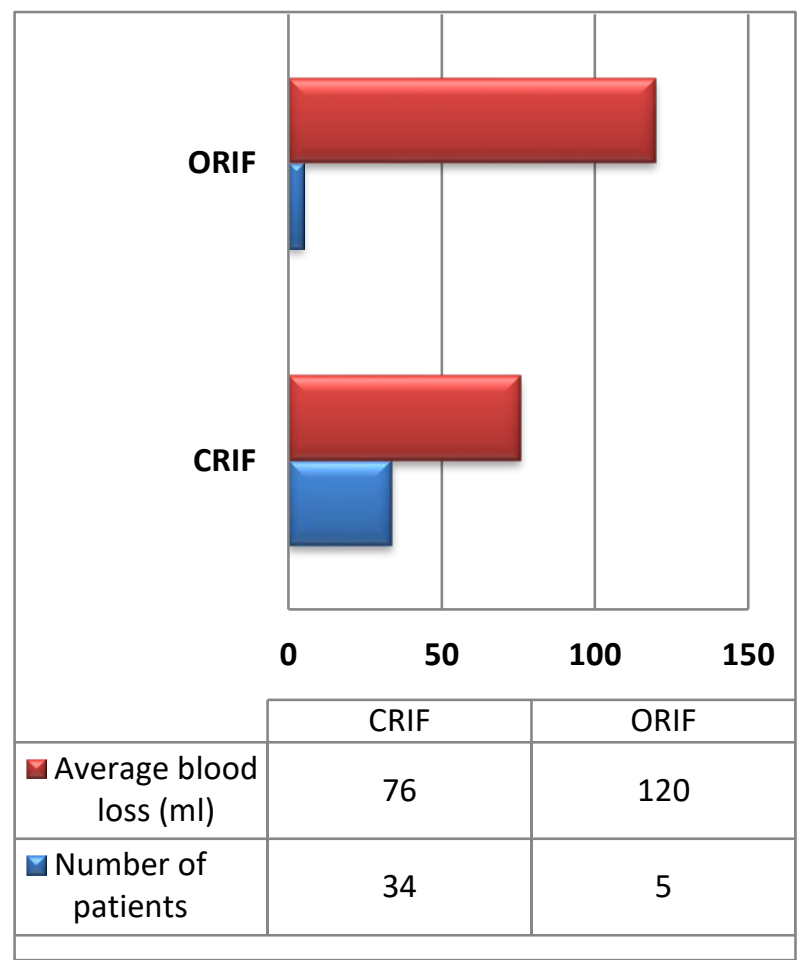

Figure 7: Average blood loss (ml).

On subsequent follow ups, 1 patient was lost to follow up. Hence the data analysis was done considering 38 patients
Fracture union was assessed radiologically on each follow ups. In our study, 8 (21.05\%) patients had incomplete union radiologically and $30(78.9 \%)$ patients had complete the union radiologically at the three months.

At 6 months, $1(2.6 \%)$ patient had back-out and $1(2.6 \%)$ patient with penetration radiologically. And in 36 $(94.7 \%)$ patients fracture was united radiologically at 6 months.

At 12 months follow-up, radiologically the fracture in all 38 patients had united.

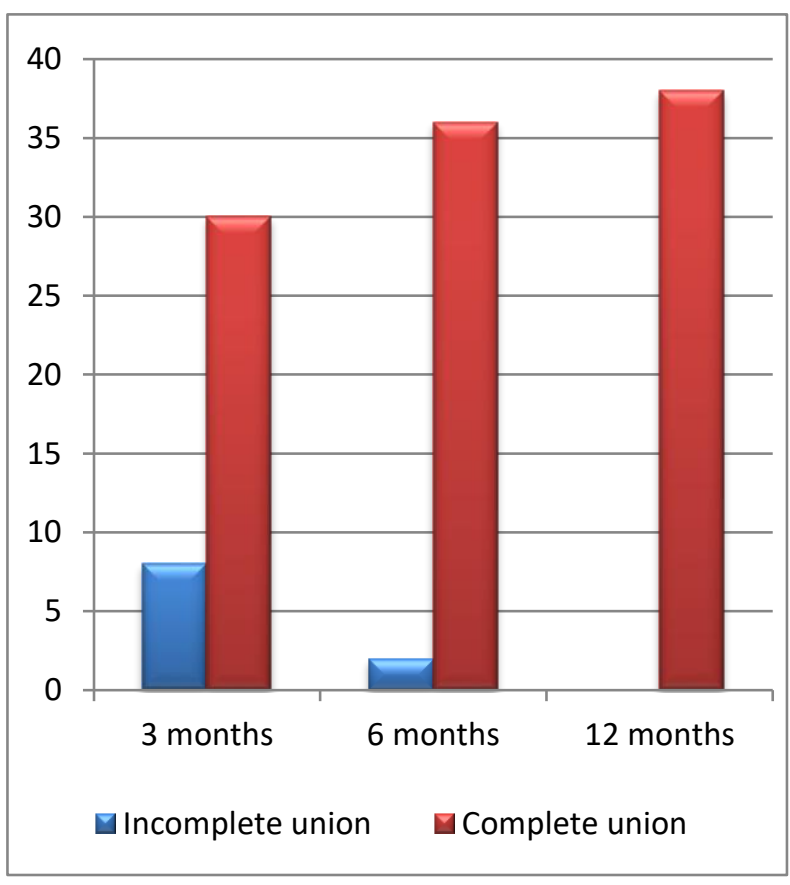

Figure 8: Radiological union of fracture.

The functional analysis was done based on the HHS as calculated on three months and the six months follow ups.

Data from the study showed that the mean HHS at three months (Mean \pm SD) of the patients was $=78.9737 \pm 6.7803$.

Table 1: Mean HHS at 3 months.

\begin{tabular}{|ll|}
\hline Variables & HHS \\
\hline Number & 38 \\
\hline Mean & 78.9737 \\
\hline SD & 6.7803 \\
\hline Minimum & 60.0000 \\
\hline Maximum & 88.0000 \\
\hline Median & 81.5000 \\
\hline
\end{tabular}

The mean HHS calculated at 6 months $($ Mean \pm SD) of patients was $=89.7895 \pm 7.4222$. 
Table 2: Mean HHS at 6 months.

\begin{tabular}{|ll|}
\hline Variables & HHS \\
\hline Number & 38 \\
\hline Mean & 89.7895 \\
\hline SD & 7.4222 \\
\hline Minimum & 60.0000 \\
\hline Maximum & 98.0000 \\
\hline Median & 90.5000 \\
\hline
\end{tabular}

\section{DISCUSSION}

The modified gamma nail with tri-wire anchorage is an effective intramedullary load-sharing device. It incorporates the principles and theoretical advantages of the Zickel nail, dynamic hip screw, and locked intramedullary nail Bellabarba et al. ${ }^{17}$ Biomechanically the modified gamma nail is stiffer and has a shorter moment arm. The extramedullary device with a longer moment arm undergoes significant stress on weightbearing and hence higher incidence of lag screw cut out and varus malunion Rosenblum et al. The larger proximal diameter $(15.5 \mathrm{~mm})$ imparts additional stiffness to the nail Rosenblum et al. Minimal blood loss, shorter operative time, and early weight-bearing are all the advantages of the gamma nail compared to extra medullary device. ${ }^{7}$

In our study, the union rate was $100 \%$ with no case of varus malunion. In the study of Herrera et al with regard to the more significant technical complications, shaft fractures and the cutting-out phenomenon were more common with the use of the gamma nail, while secondary varus occurred at a greater rate when using the PFN..$^{18}$ In our case series, the average operating time was $48 \mathrm{~min}$ and ranged from 40-55 minutes. The results were comparable to the series of Leung et al, Chen et al, Bellabarba et al. ${ }^{17,19,20}$ In our study, the average blood loss of $76 \mathrm{ml}$ and $120 \mathrm{ml}$ in cases of CRIF and ORIF respectively. The results of blood loss were comparable with Bellabarba et al, Radford, Needoff et al. ${ }^{17,21}$ There were no cases of postoperative femoral fractures. One patient had tri-wire cut through and one had tri-wire back-out. This did not hamper the functionality. Hence, no further intervention was required. No patient had mechanical failure and had minimum technical difficulties. Full weight-bearing was also early as compared to other procedures. The HHS was an average of 79 at 3 months representing a fair outcome. This subsequently increased to 90 at the six months representing an excellent outcome.

This study although done diligently has a few limitations; namely: small sample size, comparatively short follow up period of 12 months and patients were lost to long term follow up due to the prevailing CORONA pandemic and lock downs. Those patients who were satisfied with their outcome, gradually dropped out of the follow up schedule (in spite of sincere attempts to be in the contact).

\section{CONCLUSION}

Modified gamma nail with additional anchorage (Triwire construct) has distinct advantages of closed fixation technique, allows for early mobilization, early weightbearing, and lesser perioperative complications. Rehabilitation is easier with this device. Proximal lag screw insertion allows dynamic osteosynthesis at the fracture site. The gamma nail transmits weight closer to the calcar, to provide greater mechanical strength. Distal locking screws in dynamic mode help in early bone healing in case of delayed union and also provide rotational stability. Tri-wire construct placed in the femoral head provides additional rotational stability in osteoporotic bone.

Funding: No funding sources

Conflict of interest: None declared

Ethical approval: The study was approved by the institutional ethics committee

\section{REFERENCES}

1. Rockwood Green's, Fractures in adults 8th edition, volume 2 Wolters Kluwer. 2014.

2. Kovalak E, Ermutlu C, Atay T, Başal Ö. Management of unstable pertrochanteric fractures with proximal femoral locking compression plates and effect of neck-shaft angle on functional outcomes. J Clin Orthop Trauma. 2017; 8(3):20914.

3. Jain MJ, Mavani KJ, Patel D. Role of provisional fixation of fracture fragments by Steinmann-pin and technical tips in proximal femoral nailing for intertrochanteric fracture. J Clin Diagnostic Res. 2017;11(6):RC01.

4. Pathrot D, U1 Haq R, Aggarwal AN, Nagar M, Bhatt S. Assessment of the geometry of proximal femur for short cephalomedullary nail placement: An observational study in dry femora and living subjects. Indian J Orthop. 2016;50:269-76.

5. Halder SC. The Gamma nail for peritrochanteric fractures. J Bone Joint Surg. 1992;74(3):340-4.

6. Sharma V, Babhulkar S, Babhulkar S. Role of gamma nail in management of pertrochanteric fractures of femur. Indian J Orthop. 2008;42(2):212.

7. Rosenblum SF, Zuckerman JD, Kummer FJ, Tam BS. A biomechanical evaluation of the Gamma nail. J Bone Joint Surg. 1992;74(3):352-7.

8. Badarou C, Louckou EA, Zakariyaou HI, Mohammed E, Mohammed S, Abdelhalim E et al. Outcomes of surgical management of pertrochanteric fractures: About 363 cases. J Orthop Trauma Surg Related Res. 2019;14(2).

9. Han L, Liu JJ, Hu YG, Quan RF, Fang WL, Jin B et al. Controlled study on Gamma nail and proximal femoral locking plate for unstable intertrochanteric femoral fractures with broken lateral wall. Scientific Rep. 2018;8(1):1-6. 
10. Papadimitriou N, Tsilidis KK, Orfanos P, Benetou $\mathrm{V}$, Ntzani EE, Soerjomataram I et al. Burden of hip fracture using disability-adjusted life-years: a pooled analysis of prospective cohorts in the chances consortium. Lancet Public Health. 2017;2(5):e239-46.

11. Torquato DF, Bordini AF, Ferreira G, Takata ET, Trigueiro G, Basile R. The correct implant choice for transtrochanteric fracture in Brazil. Acta Ortop Brasileira. 2016;24(6):327-9.

12. Knobe M, Pape HC. Anchorage strategies in geriatric hip fracture management. Innovative Surgical Sci. 2016;1(2):73-8.

13. Adam P. Treatment of recent trochanteric fracture in adults. Orthop Traumatol. 2014;100(1):S75-83.

14. Kumar N, Kataria H, Yadav C, Gadagoli BS, Raj R. Evaluation of proximal femoral locking plate in unstable extracapsular proximal femoral fractures: Surgical technique and mid-term follow up results. J Clin Orthop Trauma. 2014;5(3):137-45.

15. Aslan A, Baykal YB, Uysal E, Atay T, Kirdemir V, Baydar ML et al. Surgical treatment of osteopetrosis-related femoral fractures: two case reports and literature review. Case Rep Orthop. 2014;2014:891963.

16. Iwakura T, Niikura T, Lee SY, Sakai Y, Nishida K, Kuroda $\mathrm{R}$ et al. Breakage of a third-generation gamma nail: a case report and review of the literature. Case Rep Orthop. 2013;2013:172352.

17. Bellabarba C, Herscovici D, Ricci WM. Percutaneous treatment of peritrochanteric fractures using the Gamma nail. Clin Orthop. 2000;375:3-42.

18. Herrera A, Domingo LJ, Calvo A, Martínez A, Cuenca J. A comparative study of trochanteric fractures treated with the Gamma nail or the proximal femoral nail. Int Orthop. 2002;26(6):3659.

19. Leung KS, So WS, Shen WY, Hui PW. Gamma nails and dynamic hip screws for peritrochanteric fractures: a randomized prospective study in elderly patients. J Bone Joint Surg. 1992;74:345-51.

20. Cheng CL, Chow SP, Pun WK. Long-term results and complications of cement augmentation in the treatment of unstable trochanteric fractures. Injury. 1989; 20(3):134-8.

21. Radford PJ, Needoff M, Webb JK. A prospective randomized comparison of the dynamic hip screw and the gamma locking nail. J Bone Joint Surg. 1993;75:789-93.

Cite this article as: Mukherjee J, Ahmad M, Jash S, Nasipuri K, Kushwaha PK. Functional outcome of peritrochanteric fracture fixation with modified gamma nail using tri-wire anchorage. Int J Res Orthop 2022;8:177-82. 